\title{
A pedagogia histórico crítica como paradigma educacional e concepção teórico-metodológica para a validação do produto educacional no profept: reflexões iniciais
}

\author{
The historical-critical pedagogy as educational paradigm and theoretical- \\ methodological conception for educational product validation at profept: early \\ thoughts
}

\section{La pedagogía histórica crítica como paradigma educativo y concepción para la validación del producto educativo profept: reflexiones iniciales}

\author{
Lago, Elen de Fátima Barros ${ }^{1}$ (São Luís, MA, Brasil) \\ ORCID ID: https://orcid.org/0000-0001-9790-7669 \\ Santos, Maria Cristina ${ }^{2}$ (São Carlos, SP, Brasil) \\ ORCID ID: https://orcid.org/0000-0002-7235-6335
}

\begin{abstract}
Resumo
A Pedagogia Histórico-Critica tem seus fundamentos teórico-metodológicos nas reflexões e na práxis pedagógica do professor Demerval Saviani que ao se contrapor ao modelo tradicional propõe um novo paradigma de ensino. É um paradigma de cunho marxista que tem como princípios o papel da educação como instrumento de desvelamento/enfrentamento das questões sociais e a escola como espaço para apropriação crítica do conhecimento partindo da realidade social, problematizando e ressignificando esta realidade. Este artigo, portanto, analisou como a Pedagogia Histórico-Critica pode contribuir para a formação docente no Programa de Pós-graduação em Educação Profissional e Tecnológica/PROFEPT, mais especificamente como este paradigma educacional pode se constituir numa possibilidade para o desenvolvimento, aplicação e validação do produto educacional a ser apresentado ao final do curso. Define-se como categorias de análise Pedagogia Histórico-Critica, formação e práxis docente. Para a compreensão do objeto de estudo e suas categorias, define-se como método de abordagem o materialismo histórico dialético e quanto aos procedimentos metodológicos trata-se de revisão de literatura e pesquisa documental que tratam do assunto analisado. Concluiu-se que nem todo os produtos educacionais apresentados ao final do programa apresentam, na sua concepção e validação, um paradigma educacional que sirva de suporte teórico-metodológico e que a PHC além de se coadunar com os princípios teóricos, metodológicos e epistemológicos do PROFEPT constitui-se um paradigma que agrega qualidade e significação aos produtos educacionais.
\end{abstract}

Palavras-chaves: Pedagogia Histórico-Crítica; PROFEPT.

\section{Abstract}

Historical-Critical Pedagogy has its methodological-theoretical tenets based in studies and pedagogical practice from professor Dermeval Saviani, who in opposition to the traditional model suggests a new teaching paradigm. It is a paradigm with Marxist nature that has as its principles the role of education as an instrument for the development / confrontation of social issues and a school as a space for critical appropriation of knowledge that starts from social reality, problematizing and re-signifying this reality.

\footnotetext{
1 Professora do PROFEPT/Programa de Pós-graduação em Educação Profissional e Tecnológica. Professora Magistério Superior do Instituto Federal de Educação, Ciência e Tecnologia do Maranhão/IFMA.. elenlago.histedbr.ma@gmail.com

2 rofessora do Programa de Pós-Graduação em Educação/UFSCar.. cbezerra@ufscar.br 
Therefore, this paper had analysed how Historical-Critical Pedagogy may contribute to teacher training in the Professional and Technological Graduate Programme (PROFEPT). Being more specific, the aim consists in understand how this educational paradigm can build it into a possibility to development, application and validation of the educational product which is the outcome at the end of the course. Historical-Critical Pedagogy, training and teaching praxis have been defined as categories of analysis. In order to understand the object of study and its categories, has been defined the dialectical historical materialism as the method of approach, and as far as methodological procedures are concerned, it consists in a literature review and documentary research that deal with the analysed subject. As a conclusion it is possible to highlight that not all educational products presented at the end of the programme have an educational paradigm that works as methodological-theoretical support into your conception and validation, and, the Historical-Critical Pedagogy, beyond of the combination with your theoretical, methodological and epistemological tenets from PROFEPT, which establishes as a paradigm that adds quality and meaning to the educational products.

Keywords: Historical-Critical Pedagogy; PROFEPT.

\section{Resumen}

La pedagogía histórico-crítica tiene sus fundamentos teórico-metodológicos en las reflexiones y en la praxis pedagógica del profesor Demerval Saviani, quien, en oposición al modelo tradicional propone un nuevo paradigma de enseñanza. Es un paradigma marxista que tiene como principios el papel de la educación como un instrumento para revelar/enfrentar los problemas sociales y la escuela como un espacio para la apropiación crítica del conocimiento de la realidad social, problematizando y reformulando esta realidad. Este artículo, por lo tanto, analizó cómo la pedagogía histórico-crítica puede contribuir a la formación del profesorado en el Programa de Posgrado en Educación Profesional y Tecnológica/ PROFEPT, más específicamente cómo este paradigma educativo puede constituir una posibilidad para el desarrollo, la aplicación y la validación. del producto educativo que se presentará al final del curso. El análisis de la pedagogía histórico-crítica, la formación y la práctica docente se definen como categorías de análisis. Para comprender el objeto de estudio y sus categorías, el materialismo histórico dialéctico se define como el método de enfoque, y en lo que respecta a los procedimientos metodológicos, es una revisión de la literatura y la investigación documental que se ocupa del tema analizado. Se concluyó que no todos los productos educativos presentados al final del programa, en su diseño y validación, tienen un paradigma educativo que sirve como soporte teórico y metodológico y que la PHC, además de estar en línea con los principios teóricos, metodológicos y epistemológicos de PROFEPT constituye un paradigma que agrega calidad y significado a los productos educativos.

Palabras-Clave: Pedagogía Histórico- Crítica; PROFEPT

\section{INTRODUÇÃO}

A educação no sistema capitalista, em particular a EPT, sempre foi alvo de reformas pautadas nas transformações da organização do trabalho e dos processos de reestruturação produtiva envolvendo inovações técnico-organizacionais. Ao governo, caberia o desenho e a execução de políticas que possam adequar os projetos educacionais, e, consequentemente, a formação do trabalhador a estas demandas, tendo como pressuposto que a classe trabalhadora persistiu/persiste "um movimento reiterado de negar à grande massa da população as oportunidades 
educacionais para uma educação básica (fundamental e média) de qualidade". (CIAVATTA, 2011, p. 173)

Barbosa (2012, p.50) afirma que muitos caminhos e discussões permeiam a história da Educação Profissional no Brasil. "Os discursos e as práticas expressavam muitas vezes o caráter funcionalista e/ou assistencialista, associado à dualidade/fragmentação existente entre o ensino médio e a educação profissional".

Para Frigotto, Ciavatta e Ramos (2012), a história da educação brasileira e da legislação para a EPT foi alicerçada no dualismo educacional que ganha status estrutural a partir da década de 1940, com a organização da educação nacional em leis orgânicas. E nesta direção analisa Ciavatta (2011, p. 171),

\begin{abstract}
A negação de uma educação básica pública, de qualidade, gratuita, universalizada para toda a população tem um contraponto controverso na ênfase à preparação estrita para o trabalho que é oferecida ao longo do século XX e nas lutas dos trabalhadores por melhores condições de trabalho [...] As políticas educacionais acompanham a industrialização, criando novas escolas e novos cursos, sem abrir mão do dualismo educacional que acompanha a estrutura da sociedade de classes e a desigualdade social no país.
\end{abstract}

Ainda segundo Frigotto, Ciavatta e Ramos (2012), nessa década, acordos assinados pelo governo brasileiro com a United States Agency for International Development (USAID) "demonstravam a intenção de se ampliar ao máximo as matrículas nos cursos técnicos e de se promover uma formação de mão de obra acelerada nos moldes exigidos pela divisão internacional do trabalho" (FRIGOTTO; CIAVATTA; RAMOS, 2012, p. 33). No geral, esses acordos foram impulsionados pela aceleração e expansão da educação nos países periféricos e vislumbravam a disseminação da ideia da educação como sinônimo de status social e geração de empregos, além de visar ao desenvolvimento econômico. Entretanto, o que no início foi marcado por uma relação amistosa e de recomendações, logo passa a ser uma relação autoritária, com exigências voltadas às demandas dos países de capitalismo avançado, os reais representantes desses organismos.

Na segunda metade da década de 1990, o governo de Fernando Henrique Cardoso apresenta ao povo brasileiro o documento "Mãos à obra, Brasil: proposta de governo" (BRASIL, 2008b) que definia as diretrizes para sua gestão. Nesse documento, o governo sinaliza para o tipo de política econômica e social que deveria 
ser adotada pelo país, priorizando um modelo de desenvolvimento articulado organicamente à economia internacional. O novo paradigma de desenvolvimento exigiria do governo e do povo brasileiro a adequação a este mundo globalizado, definido como o único projeto viável para desenvolvimento e crescimento econômico do país. O governo afirma que, "para atrair capitais, será preciso competir com os próprios países desenvolvidos [...] a política externa do país e sua política econômica interna precisam ser conjugadas para a realização dessa estratégia, que terá na expansão do mercado interno e regional uma de suas bases". (BRASIL, 2008b, p.4)

A política seria uma segurança à estabilidade econômica, ou seja, deveria garantir a continuidade dos investimentos e a redefinição dos esquemas de financiamento; propiciar a abertura para o capital estrangeiro; definir com clareza as regras negociadas internacionalmente; preservar os interesses nacionais, num processo de negociação bilateral ou multilateral, em todos os foros necessários.

Quanto à EPT, esta teria um caráter complementar e profissionalizante, tendo como objetivo maior preparar os jovens para uma vida produtiva, contando com uma clientela, constituída, principalmente, por alunos e egressos da educação básica e trabalhadores em busca de requalificação.

A partir de 2003, no que tange ao contexto político-econômico, assistiu-se no país a uma transição política e à ascensão ao governo federal de um representante do Partido dos Trabalhadores (PT) ao maior cargo do Executivo. A vitória eleitoral de Lula à Presidência da República, em 2002, sinalizou que uma parte significativa da população brasileira apostara na mudança dos rumos da política e da economia do país. E, ainda, que a proposta do PT significava uma alternativa, um novo ciclo histórico e a possibilidade da adoção de um outro modelo econômico, capaz de assegurar a retomada do crescimento marcado por menos desigualdade social.

Todo esse movimento estrutural rumo à financeirização da economia trouxe ao próprio sistema capitalista o que alguns estudiosos têm denominado de "fragilidade sistêmica", "risco sistêmico" ou "vulnerabilidade sistêmica". Economistas apontam como uma característica inerente ao próprio movimento econômico adotado, em que os empréstimos internacionais e o dinheiro investido são mais direcionados para a especulação financeira e muito menos para o financiamento da produção. 
Segundo Chesnais e Plihon (2002), esta vulnerabilidade sistêmica ou fragilidade financeira sistêmica se dá pelo fato de que a mundialização do capital está baseada em transações especulativas, que fazem circular no mercado financeiro um capital fictício. De outra forma, Singer (2012) analisa que o governo optou, a partir de 2003, pela adoção de políticas para a redução da pobreza e ativação do mercado interno, sem confrontar o regime econômico hegemônico, e, a partir de 2006, com o surgimento e apoio de sua base eleitoral - a classe subproletariada -, este fato permitiu que o governo continuasse sem nenhum entrave com esse modelo de política econômica.

É neste contexto de continuidade da política econômica, da contínua reforma do Estado para sua inserção definitiva no sistema de acumulação financeira e, ao mesmo tempo, de nascimento de um ícone da política brasileira, que foram implementadas no século $X X I$ as reformas no sistema educacional brasileiro, em particular, na EPT. No segundo mandato do Governo Lula, pela Lei 11.892/2008 (BRASIL, 2008a), é instituída a nova RFEPCT, e criados os IFETs, com adesão quase maciça de todas as instituições que faziam parte da antiga rede.

De acordo com a Lei 11.892/2008 (BRASIL, 2008a), no Capítulo I, artigo $1^{\circ}$, no que concerne à estrutura organizacional, fica instituída a Rede, no âmbito do sistema federal de ensino, vinculada ao MEC e constituída pelas seguintes instituições: Institutos Federais de Educação, Ciência e Tecnologia; Universidade Tecnológica Federal do Paraná (UTFPR); CEFET Celso Suckow da Fonseca CEFET-RJ e de Minas Gerais - CEFET-MG; Colégio Pedro II; Escolas Técnicas Vinculadas às Universidades Federais, deixando de existir, a partir deste momento, as antigas instituições, com exceção dos CEFETs citados. E esta reordenação ou nova institucionalidade exigiu que o Estado repensasse as políticas de formação de professores, em especial dos que atuavam na EPT.

Em se tratando especificamente da formação de professores no Brasil, percebe-se que, historicamente, a formação inicial dos docentes que atuam na Educação Profissional e Tecnológica (EPT) representa uma lacuna na política educacional. A Lei de Diretrizes e Bases da Educação (LDB), que deveria tratar esta questão, o faz de maneira genérica, não contemplando as especificidades da EPT, 
cabendo à sociedade civil pressionar o Estado para fomentar, nas instituições públicas e privadas, a formação continuada desses profissionais. Como afirma Machado (2008, p.14), "a carência de pessoal docente qualificado tem se constituído num dos pontos nevrálgicos mais importantes que estrangulam a expansão da educação profissional no país".

No que diz respeito exclusivamente à formação continuada, o Governo Federal propõe que esta formação se dê em cursos de pós-graduação lato sensu e stricto sensu. Quanto aos cursos stricto sensu encontram-se os mestrados acadêmicos, mestrados profissionais e doutorados, mas, segundo Machado (2008, p. 14), estas iniciativas ainda não solucionam o problema, visto que ainda persiste no país uma estrutura fragmentada na formação de professores para a EPT. A autora, em consonância com o debate acadêmico acerca dessa questão, defende que é preciso organizar uma política nacional de formação de professores para esta modalidade de ensino, visto que

\begin{abstract}
Há, hoje, ofertas formativas diversificadas de formação de docentes para este campo, mas são muito reduzidas considerando o potencial de demanda e nem sempre atendem a todos os perfis de entrada dos candidatos. Essas ofertas são constituídas por programas especiais, cursos de pós-graduação, formação em serviço e formação a distância. Poucas são, entretanto, as iniciativas de cursos de licenciatura.
\end{abstract}

Quanto aos Mestrados Profissionais (MPs), estes foram criados por meio da Portaria $n^{\circ}$ 80/1998 (BRASIL, 1998) e surgem como alternativa de formação docente num momento histórico em que o país aderia a um novo modelo de acumulação do capital, com apoio dos organismos internacionais que fomentam reformas educacionais neoliberais. Sabe-se que estes mestrados são alvo de muitas críticas, entretanto, reitera-se o entendimento das questões estruturais/conjunturais apontadas por diversos autores e compreende-se o relevante papel destes programas na formação dos docentes que, por vários motivos, não são atendidos pelos Mestrados Acadêmicos (MAs). Reiteramos nesse artigo a importância dos MP's visto que o resultado final é justamente uma atividade que nasce do diálogo entre teoria e prática, entre a acadêmica e sala de aula, em que,

[...] o ganho obtido a partir de um MP extrapola a possibilidade de um produto educacional a ser validado e disponibilizado para outros professores, mas 
amplia a oportunidade real na qual um professor se debruça sobre sua prática, avalia um problema real que o motivou a recorrer à academia e busca solução possível e pautada em reflexão teórico-metodológica. (MOREIRA, et al, 2018, p. 345)

Esta lacuna na formação é evidenciada nas estatísticas nacionais, as quais apontam que, em 2018, tínhamos 2.227.307 docentes na Educação Básica e dentre estes somente $38,1 \%$ apresentavam formação em nível superior e destes a maioria (34,9\%) na pós-graduação lato sensu. (BRASIL, 2018a)

E é nesse contexto de falta de políticas educacionais para a formação docente para a EPT que surge o Programa de Pós-graduação em Educação Profissional e Tecnológica (PROFEPT), criado através da Resolução 161/2016 (BRASIL, 2016), propiciando espaços de formação em educação profissional e tecnológica, "visando tanto à produção de conhecimentos como o desenvolvimento de produtos, por meio da realização de pesquisas que integrem os saberes inerentes ao mundo do trabalho e ao conhecimento sistematizado". (BRASIL, 2016, p. 2).

Como o PROFEPT é um mestrado profissional (MP) ao final do programa os mestrandos tem que propor, aplicar e validar um produto educacional. A Coordenação de Aperfeiçoamento de Pessoal de Nível Superior (CAPES) define produto educacional como um objeto de aprendizagem desenvolvido com base em trabalho de pesquisa científica que visa disponibilizar contribuições para a prática profissional de professores da educação básica, futuros professores, professores do ensino superior e formadores de professores.

Defende-se, portanto, que o produto educacional é mais que uma burocracia ou uma exigência de um programa para obtenção de um título. O produto educacional deve ser concebido a partir de uma prática pedagógica consciente, da inserção crítica nos espaços formativos, para apresentar à comunidade uma melhor forma de resolver/minimizar problemas do cotidiano escolar. O produto educacional, portanto, constitui-se o resultado de um processo de reflexão da vivência cotidiana da sala de aula. Ou seja, o produto educacional é "aplicado, descrevendo o desenvolvimento de processos ou produtos de caráter educativo, visando à melhoria da educação na área específica” (MOREIRA, 2004, p. 345) 
Para garantir esse processo de reflexão-ação, este produto deve ter um método de abordagem e um referencial didático-pedagógico que o sustente, que consiga captar a essência do problema e a partir desta essência pensar uma resolução eficaz. É preciso contribuir para uma formação em que supere esta constatação de que "a falta de conexão entre a teoria acadêmica e a prática social dos alunos é refletida na dificuldade que alguns estudantes têm de aplicar os conhecimentos em situações cotidianas" (ALVES; MELO; SANTOS, 2017, p. 28)

Metodologicamente este artigo contou com uma revisão de literatura e uma pesquisa documental visando perceber as lacunas nos produtos educacionais assim como as reais possibilidades da pedagogia histórica crítica como paradigma para a formação e para a concepção/validação dos produtos educacionais do PROFEPT.

\section{A PEDAGOGIA HISTÓRICO-CRITICA COMO PARADIGMA EDUCACIONAL PARA A FORMAÇÃO DOCENTE}

A Pedagogia Histórico-Crítica é uma teoria pedagógica que tem por fundamento dialética materialista como desenvolvida por Karl Marx, é a expressão teórica do marxismo no campo da educação (SAVIANI, 2005). Esta corrente pedagógica remonta sua origem a meados dos anos 1960, capitaneado pelo Professor Demerval Saviani, e, de lá para cá tem percorrido um processo de elaboração de décadas, não mais individual, mas coletivo, congregando uma gama de pesquisadores que se debruçam em estudos sobre a educação escolar, tomando como referência, o materialismo histórico dialético. Saviani (2005) destaca alguns fatores que influenciaram no surgimento dessa Pedagogia de base socialista, na década de 1970, um período de grande efervescência política, cultural, social de contestação do regime militar e suas políticas educacionais:

- experiência pessoal: inicialmente o autor destaca os aspectos pessoais, de "rica experiência" desde estudante de graduação no curso de filosofia quando vivenciou os debates sobre a reforma universitária e a resistência à ditadura evidenciando as insuficiências das políticas educacionais e limitações políticas, instigando a compreensão dos problemas enfrentados e a busca de soluções (SAVIANI, 2011), passando pela sala de aula como professor de colégios públicos e 
privados, no ensino superior e posteriormente, na pós-graduação (SAVIANI, 2005, 2011).

- participação político-pedagógica: para além do processo de formação política em um momento conturbado e violento da história brasileira, a reflexão sobre a escola e seu papel na sociedade de classes perpassava as preocupações dos educadores e a escola passou a ser estudada em sua função intrínseca a sociedade capitalista. A formulação teórica do momento, influenciada pelas ideias socialistas, partia da contestação das políticas educacionais e da pedagogia oficial do regime militar, representado pelas teorias que mais tarde Saviani classificaria como críticoreprodutivistas. De acordo com o autor, essas teorias formularam uma crítica a educação capitalista, evidenciando seu caráter reprodutor das relações sociais dominantes.

Essas teorias são teorias críticas por enfrentarem e analisarem a educação mostrando os condicionantes sociais e sua relação com o desenvolvimento do capital, por denunciarem a impossibilidade de se compreender a educação sem ter por base os esses condicionantes. Entretanto, esbarram no limite da conclusão de que a educação tem como mera função a reprodução da sociedade em que está inserida. Essas teorias buscavam explicar o fenômeno educativo sem, contudo, pretender orientar a prática pedagógica (SAVIANI, 2005).

A mobilização gerada pelas teorias crítico-reprodutivistas, o clima cultural, político e pedagógico que se instaurou no período evoluiu para busca de alternativas à orientação oficial, "o que colocava a necessidade de se elaborar uma teoria pedagógica que fosse crítica, mas não reprodutivista" (SAVIANI, 2005, p. 32).

A Pedagogia Histórico-Crítica vem então, ocupar esse vácuo como uma teoria pedagógica crítica: "busca equacionar, de alguma maneira, o problema da relação educador-educando, de modo geral, ou no caso específico da escola, a relação professor-aluno, orientando o processo ensino aprendizagem" (SAVIANI, 2005 , p. 25). É uma teoria pedagógica de base marxista, que surgiu a partir de necessidades postas pela prática dos educadores. Compreende a história a partir do seu desenvolvimento material, da determinação das condições materiais da existência humana e, além de fazer a crítica sistemática a organização escolar no capitalismo, 
prega a transformação do modo de produção, como condição para se transformar as relações sociais e, consequentemente, a escola. Está posicionada na luta de classes, como todas as teorias pedagógicas de ontem e de hoje, porém, define claramente uma posição aliando-se e defendendo os interesses da classe trabalhadora. Trata-se de uma concepção de mundo, de ser humano, um projeto de educação e sociedade.

A escola é compreendida como instituição social que tem um papel que the é específico e que difere das outras instituições educativas, qual seja, propiciar o acesso ao conhecimento sistematizado, produzido historicamente pelo conjunto dos homens e que é necessário que as novas gerações adquiram, para que possam avançar a partir do repertório cultural, cientifico, tecnológico, artístico produzido pela humanidade em seu processo histórico. A ação da escola é intencional, planejada, sistematizada e se realiza por meio do trabalho educativo, que, de acordo com Saviani (2003, p. 13), " [...] diz respeito, de um lado, à identificação dos elementos culturais que precisam ser assimilados pelos indivíduos da espécie humana para que eles se tornem humanos e, de outro lado e concomitantemente, à descoberta das formas mais adequadas para atingir esse objetivo".

Cabe a educação escolar a tarefa de identificar e selecionar os conteúdos fundamentais para o desenvolvimento e evolução do gênero humano, isto é, para a formação humana omnilateral, o desenvolvimento das funções psíquicas superiores nos indivíduos e com isso, permitir que se expressem de novas formas (MALANCHEN, ANJOS, 2016), superando, por incorporação, os conteúdos do cotidiano. Dito isto, a escola deve,

propiciar aos indivíduos aquilo que não está posto em seu ponto de partida, ou seja, o acesso à cultura erudita, ao clássico e não à cultura popular. Portanto, o ponto de partida é a cultura popular e o ponto de chegada é o conhecimento elaborado e sistematizado, ou seja, a seleção daquilo que a humanidade de melhor produziu até o momento, no campo das ciências, artes e filosofia (MALANCHEN, ANJOS, 2016, p. 122).

Ainda de acordo com os autores (2016, p. 123), definido o conteúdo do ensino a ser socializado, deve-se, ainda, determinar a melhor forma de fazê-lo, e isso pressupõe a determinação "dos métodos e processos de ensino-aprendizagem, compreendendo que a escolha de métodos e encaminhamentos no espaço da educação não é e nunca será neutro". 
Dialeticamente se relacionam nesse processo dois tipos de sujeito, o do ensino e o da aprendizagem, professor e aluno, ambos com papéis diferentes: "ao aluno cabe apropriar-se dos conteúdos transmitidos pelo professor", enquanto ao professor "cabe conhecer os elementos que estão envolvidos no processo de ensino, para que possa encaminhar sua ação de forma intencional e direcionada" (MALANCHEN, ANJOS, 2016, p. 125). Ao professor, cabe, portando, conhecer e dominar os conteúdos a serem ensinados e a melhor forma de transmiti-los, é "aquele que já se apropriou dos elementos culturais humanizadores e que organiza o trabalho pedagógico levando em conta o desenvolvimento psíquico já conquistado e aquele almejado" (MARSIGLIA e MARTINS, 2014, p. 180).

O trabalho do professor, portanto, adquire uma relevância maior considerando seu caráter, pois o produto de seu trabalho não se materializa em um objeto físico qualquer, faz parte do processo de humanização do outro e de si mesmo. O produto do trabalho educativo,

revela-se na promoção da humanização dos homens, na consolidação de condições facilitadoras para que os indivíduos se apropriem do saber historicamente sistematizado pelo gênero humano. Encontra-se a dependência do desenvolvimento genérico de seu autor e, consequentemente, em íntima relação com seu processo de personalização (MARTINS, 2015, p. 4)

Ao contrário de outros trabalhadores que, no capitalismo, foram alienados do produto do seu trabalho e essa alienação não interfere no resultado do trabalho, Martins evidencia que a alienação no trabalho do professor interfere decisivamente na qualidade do produto do seu trabalho, à medida que o "trabalho educativo pressupõe o homem diante de outro homem de quem não pode estar estranho (alienado), fundando-se numa relação que é por natureza interpessoal e mediada pelas apropriações e objetivações desses homens" (MARTINS, 2015, p. 5).

Dito isto e, ainda tomando por base, Ligia Márcia Martins (2015, p. 5) quando discute a formação da personalidade do professor, afirma que ela - a personalidade do professor - "é uma variável interveniente no processo educativo, já que educar exige claro posicionamento político e pedagógico, pressupõe a ação intencional do educador a todo momento, implica permanentes tomadas de decisões". 
Considerando as especificidades do trabalho do professor e da escola, convém então pensar na formação desse profissional. Inicialmente, como proposto pela Pedagogia Histórico-crítica, "a formação de qualquer profissional, aqui em especial a de professores, como uma trajetória de formação de indivíduos, intencionalmente planejada, para a efetivação de determinada prática social" (MARTINS, 2010, p. 14)

Acreditamos que a formação deve contemplar as apropriações do patrimônio físico e simbólico produzido historicamente pelo trabalho dos homens, valorizar o domínio da teoria, da objetividade e da racionalidade expresso nos conhecimentos clássicos, universais, condição necessária para a compreensão do real. Junto a isso, um sólido domínio dos avanços técnicos, filosóficos, científicos do campo específico de atuação.

\section{A FORMAÇÃO DOCENTE NO PROFEPT E A PEDAGOGIA HISTÓRICO-CRÍTICA}

É consenso no debate educacional que, em meados do século $X X$, o país adere à política neoliberal e, para atender as exigências da reestruturação produtiva, adotou amplas mudanças políticas e econômicas, entre as quais as reformas educacionais da educação básica a educação superior.

No que diz respeito à Educação Profissional e Tecnológica (EPT), o Governo Federal expandiu a oferta de vagas por meio da criação de uma nova institucionalidade para a Rede Federal de Educação Profissional, Científica e Tecnológica (RFEPCT). Esta nova rede é composta pela fusão ${ }^{3}$ da maioria das instituições federais que já constituíam a rede.

Desta expansão surge a necessidade de ofertar programas que dessem conta da formação dos profissionais (docentes e técnicos-administrativos) que atuavam e os que iriam atuar nesta modalidade de ensino e foi nesse contexto que a Secretaria de Educação Profissional e Tecnológica do Ministério da Educação (SETEC/MEC)

\footnotetext{
3 Desde 29 de dezembro de 2008, 31 Centros Federais de Educação Tecnológica (CEFETs), 75 Unidades Descentralizadas de Ensino (Uneds), 39 Escolas Agrotécnicas, 7 Escolas Técnicas Federais e 8 Escolas vinculadas a Universidades deixaram de existir para formar os Institutos Federais de Educação, Ciência e Tecnologia. De acordo com a Plataforma Nilo Peçanha (2019), no Brasil existem: 647 unidades, 11.766 cursos e 964.593 matrículas.
} 
incentivou as instituições para a implementação de programas de pós-graduação em rede. Desta forma,

Ante o exposto, o Conselho Nacional das Instituições da Rede Federal de Educação, Científica e Tecnológica (CONIF), com o apoio da SETEC/MEC, incentivou a proposição do Mestrado Profissional em Educação Profissional em Rede Nacional (ProfEPT), em função da necessidade de aperfeiçoar as práticas educativas e a gestão escolar vinculadas à EPT, em articulação com a demanda por qualificação de profissionais da rede, mas também abrindo possibilidades de formação qualificada ao público em geral, aproveitando a grande capilaridade de atuação territorial da RFEPCT para otimizar a oferta das vagas do Programa.(BRASIL, 2020, p. 1)

E dentre essas iniciativas, destaca-se o Programa de Pós-Graduação em Educação Profissional e Tecnológica (PROFEPT) ${ }^{4}$ que se constitui um programa de excelência ,que proporciona a formação nos princípios que defendemos neste artigo e abordamos na seção anterior. É um programa da área de ensino da CAPES e vem contribuindo para uma grande lacuna na formação docente, visto que segundo a Sinopses Estatísticas da Educação Básica (BRASIL, 2018a), no ano de 2018, apresentava que $20,1 \%$ de professores no país atuavam sem a devida formação no ensino superior.

Dos 2.227.307 professores da Educação Básica do País, "847.328 (38,1\%) docentes têm formação em nível de pós-graduação. Ao considerar-se os cursos de Mestrado e Doutorado, observa-se que somente 3,1\% dos docentes têm a formação nesse nível, extremamente baixo que evidencia uma demanda para formação de mestre e doutores". (BRASIL, 2018b, p. 12)

Tabela 1 - Número de Docentes da Educação Básica com Formação Acadêmica em nível de Pós-Graduação, segundo a Região Geográfica - 2018

\begin{tabular}{|l|c|c|c|c|c}
\hline \multirow{2}{*}{ País/Regiões } & \multicolumn{3}{|c}{ Docentes com formação em nível de Pós-Graduação } \\
\cline { 2 - 5 } & $\begin{array}{c}\text { Docentes } \\
\text { da } \\
\text { Educação } \\
\text { Básica }\end{array}$ & $\begin{array}{c}\% \text { Especialização } \\
\text { Lato sensu }\end{array}$ & $\begin{array}{c}\% \\
\text { Mestrado }\end{array}$ & $\begin{array}{c}\% \\
\text { Doutorado De }\end{array}$ & $\begin{array}{c}\text { Docentes } \\
\text { com Pós- } \\
\text { Graduação }\end{array}$ \\
\hline
\end{tabular}

\footnotetext{
${ }^{4}$ O PROFEPT é um programa de pós-graduação com um curso de mestrado profissional em Educação Profissional e Tecnológica ofertado em rede nacional, pertencente à área de Ensino e reconhecido pela Coordenação de Aperfeiçoamento de Pessoal de Nível Superior - CAPES do Ministério da Educação. (BRASIL, 2018).
} 
Fortaleza-CE-Brasil

\begin{tabular}{l|c|c|c|c|c}
\hline Brasil & 2.227 .307 & 34,9 & 2,6 & 0,5 & 38,1 \\
\hline Norte & 196.831 & 26,4 & 1,9 & 0,3 & 28,6 \\
\hline Nordeste & 624.787 & 31,9 & 2,3 & 0,4 & 34,5 \\
\hline Centro-Oeste & 166.146 & 38,3 & 3,1 & 0,5 & 41,9 \\
\hline Sul & 903.549 & 30,8 & 2,5 & 0,5 & 33,8 \\
\hline Sudeste & 335.994 & 54,9 & 3,9 & 0,7 & 59,5 \\
\hline
\end{tabular}

Fonte: Brasil (BRASIL, 2018b, p. 13).

O PROFEPT a cada ano vem, com êxito, lançando editais para o ingresso de novos alunos através do Exame Nacional de Acesso(ENA) ${ }^{5}$, que de 2017 a 2020 recebeu, aproximadamente, 122.751 inscritos, demonstrando que o programa vem atraindo o interesse da sociedade civil que almeja atuar na EPT. E deste modo o programa, no ano de 2019, já matriculou cerca de 2.062 profissionais distribuídos em 38 Instituições Associadas $/ \mathrm{IAs}^{6}$ e sob a responsabilidade de aproximadamente 493 docentes. Sendo de responsabilidade das IAs,

\begin{abstract}
São requisitos gerais aplicáveis às Instituições interessadas: I - Assegurar o caráter inteiramente gratuito do Programa na instituição; II - Proporcionar corpo docente com pelo menos 8 (oito) docentes permanentes, com dedicação mínima de 15 horas ao programa, com título de doutor e experiência compatível ao objetivo do Programa, lotados em uma das instituições previstas no Art. 30 desse regulamento, sendo mais de $50 \%$ deles vinculados à Instituição Proponente e com qualificação acadêmica e técnica, prevista no Edital, que permitam assegurar a regularidade e a qualidade das atividades de ensino, pesquisa, extensão e de orientação; III - Apresentar infraestrutura física adequada e indicada no Edital para o desenvolvimento das atividades previstas no Programa; IV - Dispor de acesso a equipamentos de informática atualizados, a rede mundial de computadores e a fontes de informação multimídia para os docentes e discentes; $V$ - Apresentar resultado do Índice Geral de Cursos (IGC-MEC) maior ou igual a 3, quando for o caso; VI - Comprometer-se com o correto cumprimento dos regulamentos, regimentos e instruções nacionais com vistas a constituir a unidade da rede. (BRASIL, 2020, p. 2)
\end{abstract}

Por assumir o materialismo histórico-dialético como referencial teóricometodológico, o programa tem como princípios: a articulação entre trabalho e educação, a formação humana omnilateral/integral, a educação politécnica e o

\footnotetext{
${ }^{5}$ Anualmente são ofertadas 24 vagas, sendo 12 para profissionais que compõem o quadro funcional da RFEPCT e 12 vagas para ampla concorrência (público externo à instituição).

${ }^{6}$ Quanto a distribuição das IAs por região: Norte/07, Nordeste/11, Sul/06, Sudeste/10, Centro-Oeste/04.(BRASIL, 2020).
} 
trabalho como princípio educativo. Estes princípios são articulados em uma área de concentração buscando aprofundar o debate acerca da EPT em espaços formais e não formais articulados ao mundo do trabalho e à produção do conhecimento de maneira interdisciplinar, visando à integração dos campos do Trabalho, Ciência, Cultura e Tecnologia. (BRASIL, 2018c).

Esta área de concentração que trata especificamente da Educação Profissional e Tecnológica/EPT está articulada em duas linhas de pesquisa, que por sua vez dividem-se em Macroprojetos de Pesquisa: Linha- Práticas Educativas em EPT (Macroprojeto 1 - Propostas metodológicas e recursos didáticos em espaços formais e não formais de ensino na EPT; Macroprojeto 2 - Inclusão e diversidade em espaços formais e não formais de ensino na EPT; Macroprojeto 3 - Práticas Educativas no Currículo Integrado) e Linha - Organização e Memórias de Espaços Pedagógicos na Educação Profissional e Tecnológica (Macroprojeto 4 - História e memórias no contexto da EPT; Macroprojeto 5 - Organização do currículo integrado na EPT; Macroprojeto 6 - Organização de espaços pedagógicos da EPT).

A matriz curricular do programa foi pensada e é trabalhada no mestrado de maneira a propiciar um espaço formativo em que os cursistas reflitam sobre as bases conceituais da EPT e consigam perceber a importância de uma atuação emancipadora em sala de aula e que efetivamente propicie uma formação humana integral. Neste sentido, o currículo é articulado nesta perspectiva, conforme demonstra abaixo,

\section{Quadro 1 - Matriz Curricular do PROFEPT}

\begin{tabular}{l|c}
\hline \multicolumn{1}{c|}{ DISCIPLINAS } & créditos \\
\hline Bases Conceituais para a Educação Profissional e Tecnológica & 4 \\
\hline Metodologia de Pesquisa & 4 \\
\hline Seminário de Pesquisa & 2 \\
\hline Teorias e Práticas do Ensino e Aprendizagem & 4 \\
\hline $\begin{array}{l}\text { Obrigatória da Linha 1: Práticas Educativas em Educação Profissional e Tecnológica } \\
\text { Obrigatória da Linha 2: Organização e Memórias de Espaços Pedagógicos em } \\
\text { Educação Profissional e Tecnológica }\end{array}$ & 4 \\
\hline Redação de Projeto de Pesquisa & 2 \\
\hline
\end{tabular}




\begin{tabular}{l|c}
\hline Prática de Ensino Orientada & 4 \\
\hline Eletiva 1 & 2 \\
\hline Eletiva 2 & 2 \\
\hline Eletiva 3 & 2 \\
\hline Prática de Pesquisa Orientada & 2 \\
\hline & 32 \\
\hline
\end{tabular}

Fonte: BRASIL, 2018c.

As disciplinas eletivas são ofertadas, na modalidade Educação a Distância (EAD), propiciando aos alunos mais opções para completar sua formação crítica. As disciplinas estão sempre articuladas a EPT e são elas: Juventude, Trabalho e Escola; História da Ciência, da Técnica e da Tecnologia; Formação de Professores para Educação Profissional e Tecnológica; Espaços Não-Formais na Educação Profissional e Tecnológica; Educação do Campo; Educação e Tecnologias; Educação de Jovens e Adultos; Políticas Públicas em Educação Profissional e Tecnológica; Produção de Recursos Educacionais; Currículo e Formação Integrada; Diversidade e Inclusão; Ciência, Tecnologia, Sociedade e Ambiente; Avaliação nos Espaços Educativos; Tópicos Especiais em Educação Profissional e Tecnológica.

Ao final do programa, os mestrandos devem apresentar um produto educacional, conforme definido pela CAPES (BRASIL, 1998, p. 1) como uma,

d) exigência de apresentação de trabalho final que demonstre domínio do objeto de estudo, (sob a forma de dissertação, projeto, análise de casos, performance, produção artística, desenvolvimento de instrumentos, equipamentos, protótipos, entre outras, de acordo com a natureza da área e os fins do curso) e capacidade de expressar-se lucidamente sobre ele.

O produto educacional, portanto, é fruto de uma pesquisa aplicada e tem como objetivo apresentar a comunidade uma nova forma ou maneira de perceber e resolver um problema do cotidiano da sala de aula. Nesse sentido, entende-se que,

os PE para além dos materiais educativos e dos objetos de aprendizagem, uma vez que além de estarem expressos em modos representativos de um texto, em forma multimodal e em uma conjunção de modos semióticos (escrito, visual, sonoro, gestual, e outros),são, em sua maioria, criados, elaborados, validados por docentes da escola básica durante a sua formação continuada (MOREIRA, et al, 2018, p. 345). 
A relevância do produto educacional está, portanto, justamente no fato de que ele pode gerar ensinamentos aos mestrandos, assim como, nos sujeitos da pesquisa tornando este intercambio uma atividade alicerçada na criticidade, reflexão e contextualização. Ou seja, o produto educacional é gerado a partir e para uma prática pedagógica.

Como docente do programa, percebemos que neste momento de pensar e validar o produto educacional os alunos têm dificuldade de aplicar os princípios do materialismo histórico-dialético e os fundamentos da EPT, nos parece que os mestrandos tem dificuldades "em considerar a história como processo e a história como método". (CIAVATTA, 2011, p. 173), ou seja, há uma tendência em dicotomizar categorias que no materialismo histórico dialético se articulam e são imbricadas. E esta dificuldade foi percebida na análise de vários produtos educacionais estudados para a reflexão deste artigo, coletados através do EDUCAPES.

Compreende-se que esta dificuldade seja, dentre outros fatores, uma herança do ensino positivista que ainda persiste nas escolas, em que os conhecimentos e as práticas pedagógicas são implementados para organizar, potencializar e legitimar o projeto educativo do capital. E desta dificuldade surge essa reflexão: como contribuir para que os mestrandos consigam inserir-se na escola e desenvolvam o produto com essa lucidez requerida ao final do curso? Em que medida a pedagogia histórico-critica pode contribuir na reflexão desse produto educacional e, mais que isso, como ela pode efetivamente propiciar uma resolução de problemas do cotidiano escolar?

É preciso propiciar/possibilitar que os mestrandos pensem e ajam dialeticamente. Pensar dialeticamente e ter o materialismo histórico dialético como método de investigação não se constitui uma tarefa fácil, pois requer o reconhecimento da concretude, da totalidade e da dinâmica dos fenômenos sociais que são construídos historicamente, é preciso "reproduzir os processos históricos no nível do pensamento, como concreto pensado, na reflexão teórica". (CIAVATTA, 2011). Compreendendo o fenômeno sem o olhar linear e apático próprio da nossa formação escolar, que cristaliza a realidade tornando-a inacessível ou inquestionável. É, portanto, vislumbrar uma ação efetiva que possa modificar a realidade que está 
sendo vivenciada. É articular a todo momento a teoria e a prática, é trabalhar no espaço da contradição, totalidade, mediação, reprodução e contrahegemonia.

Compreende-se que a pedagogia histórico-crítica é essa proposta revolucionária para refletir os processos educacionais e de atuação didáticopedagógica nos espaços formais de ensino. Os fundamentos deste paradigma estão alicerçados na defesa de uma escola pública que atenda os anseios da classe trabalhadora e como tal proposição requer dos professores o entendimento critico/reflexivo acerca das questões sociais, políticas e econômicas.

E é neste sentido que utilizar a pedagogia histórico-critica como fundamento de ensino para a concepção e validação o produto educacional do PROFEPT contribui, sem dúvida, para um produto mais próximo ao que se propõe o programa, na medida em que este paradigma defende que " a educação é influenciada por elementos sócio-políticos; que há uma relação dialética no processo educativo; e que há critérios de desenvolvimento a serem observados". (ALVES; MELO; SANTOS, 2017, p. 30)

Saviani (2010), em contraposição aos modelos tradicionais de ensino e por meio da sua práxis pedagógica delineou os princípios da pedagogia histórico-critica, afirmando a vinculação dialética entre sala de aula e realidade social e, para sua efetivação, propôs cinco passos ou momentos: prática social inicial, problematização, instrumentalização, catarse e prática social final. Seguindo esses passos, articulados dialeticamente, o indivíduo poderia acessar o conhecimento criticamente, "pela elaboração das funções psíquicas superiores, próprias da cultura humana à medida que se rompe com o imediatismo e se apropria dos signos". (MENDES, BIANCOM, FAZAN, 2019, p.818)

Refletir sobre o cotidiano escolar, como afirma lanni (2011), é uma tarefa de aproximação obstinada e reiterada desse espaço, devido às inúmeras determinações ideológicas e político-econômicas em que este espaço está inserido. A escola nos moldes do capitalismo é um espaço de legitimação de uma classe social, dos conteúdos da classe que detém o poder, mas é, também, um espaço rico de possibilidades que devem ser apropriadas pela classe que vive da venda do trabalho. A atividade complexa de perceber essa contradição está posta para os educadores 
como um desafio a mais da sua práxis pedagógica e, para uma atividade de tal complexidade, é preciso que esse olhar esteja embasado em pressupostos científicos e críticos.

Quando percebemos os princípios que são requeridos para a EPT formação omnilateral politécnica; trabalho como princípio educativo e articulação entre trabalho e educação - vislumbramos que a pedagogia histórico-crítica é uma proposta que se coaduna com estes princípios. Percebe-se a relevância da pedagogia históricocrítica principalmente por que entende-se que,

[...] que a educação é um fenômeno complexo e dinâmico, requer diálogo, trocas e estudos sobre seus fins e objetivos. A abordagem dos conteúdos e a metodologia aplicada no processo educativo são fundamentais para desenvolver as capacidades intelectuais dos estudantes e promover tanto a ampliação dos sentidos quanto práticas sociais que desenvolvam os sujeitos cognitivamente e socialmente. (ALVES; MELO; SANTOS, 2017, p. 27)

E é nesse sentido que a pedagogia histórica-crítica encontra espaço profícuo para atuar e contribuir, na medida em que ao propiciar o diálogo, a reflexão e autonomia dos atores envolvidos no complexo ato de educar e no espaço da formação dos docentes, como é o caso dos mestrandos do PROFEPT que não apenas refletirão uma realidade mas tem como meta final observar, refletir e propor uma ação efetiva no cotidiano da escola através do produto educacional.

É preciso defender que o produto educacional a ser validado no PROFEPT articule criticamente esses princípios e que estes $s$ estejam presentes deste a concepção até a validação do produto. Caso o programa não garanta a defesa desses princípios corremos o risco de, mais uma vez, legitimarmos uma formação docente que não opere efetivas mudanças no espaço da escola e, muito menos, que garanta a defesa dos pressupostos definidos como essenciais para a formação da classe trabalhadora.

Todos esses pressupostos podem ser mobilizados pelo mestrando do PROFEPT ao se debruçar sobre o seu trabalho e produto final. Refletir sobre o produto educacional tendo este suporte epistemológico e teórico-metodológico oportunizará maior aproximação e a efetiva apropriação do objeto estudado e, sem dúvida, este produto suscitará a reflexão crítica dos sujeitos/alvo da pesquisa. 


\section{CONSIDERAÇÕES FINAIS}

A formação docente para a EPT constitui-se um desafio para os educadores e para os formuladores da política educacional no país. Refletir sobre os princípios e fundamentos que devem estar presentes na formação dos docentes que atuam na EPT e para a qualificação dos trabalhadores que estão matriculados nesta modalidade de ensino é uma tarefa complexa devido à própria dinâmica do processo produtivo.

Nesse sentido, a proposta educacional defendida pelo PROFEPT de base marxiana sustenta que a escola da EPT precisa: acompanhar as transformações do mundo do trabalho, compreender a indissociabilidade entre formação escolar e processo produtivo; defender que a formação humana seja integral e politécnica; que os docentes que atuam ou atuarão na EPT precisam ter uma formação que contemple as especificidades da EPT; que os profissionais da educação que atuam ou atuarão na EPT tenham um projeto educacional revolucionário e, acima de tudo, das necessidades formativas do trabalhador.

O PROFEPT surge justamente para atender a esta complexidade e lacuna na política de formação docente no país, mas para se constituir num programa que efetivamente contribua para o debate sobre a formação do trabalhador é preciso que ele garanta que os produtos educacionais, fruto dessa formação, consigam dar conta de perceber a realidade da escola em suas múltiplas determinações, produzindo um conhecimento que reflita estas determinações e oportunize ações para superação das dificuldades da escola.

Finalmente e não menos importante, o processo de formação deve levar o sujeito a compreensão dos limites impostos pela sociedade capitalista ao pleno e verdadeiro desenvolvimento dos indivíduos. Se, a verdadeira educação, como pressupõe a Pedagogia Histórico-crítica, é a "transformação do ser em direção a um ideal humano superior", os esforços para a transformação do indivíduo se tornam indissociáveis dos esforços para a transformação da sociedade (MARTINS, 2015, p.134).

\section{Referências}


ALVES, Clarice G.R; MELO, Lana C. B.; SANTOS, Virginia M. da S. A. dos. Relações entre pedagogia histórico-crítica, psicologia histórico-cultural e o conceito de atividade de Leontiev. Revista Labor Fortaleza/CE, jan/jul 2017 Vol. 01, $\mathrm{n}^{0}$ 17, p. 27-41. Disponível em: http://www.periodicos.ufc.br/labor/article/view/13950/30252. Acesso em: 12/07/2020.

BARBOSA, Ana Cecília C. Os Institutos Federais: reflexões sobre a ifetização a partir do processo de elaboração do Regimento Geral do IFS. 2012. Dissertação (Mestrado em Psicologia Social). Núcleo de Pós-Graduação e Pesquisa em Psicologia Social, Universidade Federal de Sergipe, Sergipe, 2012. Disponível em:< http://bdtd.ufs.br/tde_busca/arquivo.php?codArquivo=979 >. Acesso em: 08/08/2014.

BOMFIM, Alexandre Maia do; VIEIRA, Valéria ; DECCACHE-MAIA, Eline. A crítica da crítica dos mestrados profissionais: uma reflexão sobre quais seriam as contradições mais relevantes. Revista Ciências e Educação, Bauru, v. 24, n. 1, p. 245-262, 2018. Disponível em: https://www.scielo.br/pdf/ciedu/v24n1/1516-7313-ciedu-24-010245.pdf. Acesso em: 19/06/2020.

BRASIL. CAPES. Portaria Nº 080, de 16 de dezembro de 1998. Brasília: CAPES, 1998.

https://www.capes.gov.br/images/stories/download/avaliacao/avaliacao-n/1892015Portaria-CAPES-080-1998.pdf. Acesso em: 20/05/2020.

BRASIL. Lei $\mathbf{n}^{\circ}$ 11.892/2008. Brasília: Presidência da República, 2008a. Disponível em: $\quad$ http://www.planalto.gov.br/ccivil 03/ Ato2007-2010/2008/Lei/L11892.htm. Acesso em: 18/06/2020.

BRASIL. Mãos à obra, Brasil: proposta de governo [online]. 2008b. Rio de Janeiro: Centro Edelstein de Pesquisa Social, 2008b. Disponível em :< $<$ http://books.scielo.org> Acesso em: 21/11/2015.

BRASIL. Resolução do Conselho Superior n 161/2016. Espirito Santo: IFES, 2016. Disponível em: https://profept.ifes.edu.br/images/stories/ProfEPT/Turma2017/Documentos/Res_CS_ 161_2016_Cria_o_Programa_de_P\%C3\%B3sgradua\%C3\%A7\% $\%$ C3\%A3o_em_Ëduca\%C3\%A7\%C3\%A3o_Profissional_e_Tecnol \%C3\%B3gica_e_aprova_seu_Regulamento_interno.pdf.pdf. Acesso em: $\overline{20 / 05 / 2020}$.

BRASIL. Lei $\mathbf{n}^{\circ}$ 9.394/1996. Brasília: Senado Federal, Coordenação de Edições Técnicas, $2017 . \quad$ Disponível em: https://www2.senado.leg.br/bdsf/bitstream/handle/id/529732/lei de diretrizes e bas es 1ed.pdf. Acesso em: 20/05/2020.

BRASIL. INEP. Instituto Nacional de Estudos e Pesquisas Anísio Teixeira. Sinopses Estatísticas da Educação Básica. 2018a. Disponível em: < 
http://portal.inep.gov.br/basica-censo-escolarsinopse-sinopse>Acesso

em: 03/06/2019.

BRASIL. CAPES. Documento de área 46/Ensino. Brasília: CAPES, 2018b. Disponível em: http://capes.gov.br/images/Documento de \%C3\%A1rea 2019/ENSINO.pdf. Acesso em: 20/05/2020.

BRASIL. Regulamento do PROFEPT. Espirito Santo: IFES, 2018c. Disponível em: https://profept.ifes.edu.br/images/stories/ProfEPT/Turma_2018/Regulamento/Res_C S_22_2018_-_Regulamento.pdf. Acesso em: 20/05/2020.

BRASIL. Plataforma Nilo Peçanha. Brasília: SETEC/MEC, 2019. Disponível em: http://plataformanilopecanha.mec.gov.br/. Acesso em: 20/05/2020.

\section{BRASIL. Programa de Pós-graduação em Educação Profissional e Tecnológica/PROFEPT. Espirito Santo: IFES, 2020. Disponível em:} https://profept.ifes.edu.br/doc. Acesso em: 20/05/2020.

CHESNAIS, François; PLIHON, D. (coord.). As armadilhas do capital: apelo dos economistas para se sair do pensamento utópico. Lisboa: Campo da Comunicação, 2002.

CIAVATTA, Maria. A cultura do trabalho e a educação plena negada. Revista Labor, n.5, v.1, p.170-189, 2011. Disponível em: http://www.revistalabor.ufc.br/Artigo/volume5/9 Maria Ciavatta.pdf. Acesso em: 19.07.2020.

COSTA, Elen de Fátima Lago Barros. Trabalho e carreira docente nos Institutos Federais de Educação, Ciência e Tecnologia. 2016. (Tese de Doutorado no Programa de Pós-graduação em Educação/UFSCar). São Carlos/SP: UFSCar, 2016. 265 p. Disponível em: Acesso em:

FRIGOTTO, Gaudêncio; CIAVATTA, Maria; RAMOS, Marise. A gênese do Decreto n. 5154/2004: um debate no contexto controverso da democracia restrita. 2012. In: FRIGOTTO, Gaudêncio; CIAVATTA, Maria; RAMOS, Marise (org). Ensino Médio Integrado: concepções e contradições. São Paulo: Cortez, 2012.

IANNI, Octávio. A construção da categoria. Revista HISTEDBR On-line, Campinas, número especial, p. 397-416, 2011. Disponível em: https://periodicos.sbu.unicamp.br/ojs/index.php/histedbr/article/view/8639917/7480. Acesso em: 12/09/2018.

MACHADO, L. R. de S. Diferenciais inovadores na formação de professores para a educação profissional. Revista Brasileira de Educação Profissional e Tecnológica, Brasília, DF, v. 1, n. 1, p.8-28 jun. 2008. Disponível em: http://www2.ifrn.edu.br/ojs/index.php/RBEPT/article/view/2862.

Acesso em: 19/06/2020. 
MALANCHEN, Julia; ANJOS, Ricardo Eleotério dos. O papel do currículo escolar no desenvolvimento humano: contribuições da pedagogia histórico-crítica e da psicologia histórico-cultural. In Germinal: Marxismo e Educação em Debate, Salvador, v. 5, n. 2, p. 118-129, dez. 2013.

MARSIGLIA, Ana Carolina Galvão; MARTINS, Lígia Márcia. Contribuições gerais para o trabalho pedagógico em salas multisseriadas. In Revista HISTEDBR On-line, Campinas, $n^{\circ} 51$, p. 383-385, jun 2013.

MARTINS, L. M. A formação social da personalidade do professor: um enfoque vigotskiano. $2^{\mathrm{a}}$ ed. Campinas: Autores Associados, 2015.

MARTINS, Lígia Márcia. O legado do século XX para a formação de professores. In MARTINS, Lígia Márcia; DUARTE. Newton (orgs.). Formação de professores: limites contemporâneos e alternativas necessárias. São Paulo: Cultura Acadêmica, 2010. Pp.13 a 31.

MENDES, Carolina Borghi; BIANCON, Mateus Luiz; FAZAN, Paulo Borges. Interlocuções entre a Pedagogia Histórico-Crítica e a Psicologia Histórico-Cultural para o ensino de Ciências. Revista Ciência e Educação, (Bauru), Bauru , v. 25, n. 3, p. 815-831, Setembro, 2019 . Disponível em: $<$ http://www.scielo.br/scielo.php?script=sci_arttext\&pid=S151673132019000300815\&Ing=en\&nrm=iso>. Acesso em: 19/06/2020.

MOREIRA, M. A. O mestrado (profissional) em ensino. Revista Brasileira de PósGraduação, ano 1, n. 1, p. 131-142, 2004. Disponível em: http://ojs.rbpg.capes.gov.br/index.php/rbpg/article/view/26. Acesso em: 29/06/2020.

MOREIRA, Maria Cristina do A.; ROÇAS, Gisele; PEREIRA, Marcus Vinicius.; DOS ANJOS, Malyta B. Produtos educacionais de um curso de mestrado profissional em ensino de ciências. Revista Brasileira Ensino de Ciências. Tecnol., Ponta Grossa, v. $11, \quad$ n. 3 , p. 344-363, set./dez. 2018. Disponível em: http://ojs.rbpg.capes.gov.br/index.php/rbpg/article/view/26. Acesso em: 29/06/2020.

SAVIANI, D. Escola e democracia. 34. ed. Campinas: Autores Associados, 2010.

SAVIANI, D. Pedagogia histórico-crítica: primeiras aproximações. 8.ed. Campinas: Autores Associados, 2003.

SAVIANI, D. Trabalho e educação: fundamentos ontológicos e históricos. Revista Brasileira de Educação v. 12 n. 34 jan./abr. 2007. Disponível em: https://www.scielo.br/pdf/rbedu/v12n34/a12v1234.pdf. Acesso em: 26/08/2017.

SAVIANI, Dermeval. Antecedentes, origem e desenvolvimento da pedagogia histórico-crítica. In MARSIGLIA, A. C. G. (org.). Pedagogia histórico-crítica: 30 anos. Campinas: Autores Associados, 2011. pp. 197-225. 
SAVIANI, Dermeval. Contextualização histórica e teórica da pedagogia históricocrítica. In: D. SAVIANI, Pedagogia histórico-crítica: primeiras aproximações, 8.ed. Campinas: Autores Associados, 2003. p. 111-125.

SAVIANI, Dermeval. Educação socialista, Pedagogia Histórico-Crítica e os desafios da sociedade de classes. In LOMBARDI, José Claudinei e SAVIANI, Dermeval (orgs.) Marxismo e Educação debates contemporâneos. Campinas, SP: Autores Associados, 2005. Pp. 223-274.

SINGER, André. Os sentidos do Lulismo: reforma gradual e pacto conservador. São Paulo: Companhia das Letras, 2012.

\section{Elen de Fátima Lago Barros Costa}

São Luís, MA, Brasil

Doutora em Educação pela Universidade Federal de São Carlos/UFSCAR (2016). Professora do PROFEPT/Programa de Pós-graduação em Educação Profissional e Tecnológica. Professora Magistério Superior do Instituto Federal de Educação, Ciência e Tecnologia do Maranhão/IFMA. Líder do Grupo de Pesquisa Estado, Trabalho e Educação. Pesquisadora do Grupo de Estudos e Pesquisas em Educação do Campo/GEPEC/UFSCAR.

Email: elenlago.histedbr.ma@gmail.com

Link do Lattes: http://lattes.cnpq.br/4214548964349807

\section{Maria Cristina dos Santos}

São Carlos, SP, Brasil

Professora Associada no Departamento de Educação da Universidade Federal de São Carlos DED/UFSCar. Doutora em Educação pela Universidade Estadual de Campinas (2007). Pós-doutora em "Ambiente e Sociedade. Pós-doutora em Educação pelo Instituto de Educação da Universidade de Lisboa (2017). Professora do Programa de Pós-Graduação em Educação/UFSCar.

Email: cbezerra@ufscar.br

Link do Lattes: http://lattes.cnpq.br/1095065753077001

Recebimento: 29/06/2020

Aprovação: $16 / 09 / 2020$

\section{Q.Code}


Revista Labor

Programa de Pós-graduação em Educação, Universidade Federal do Ceará

Fortaleza-CE-Brasil

Prof. Dr. Enéas de Araújo Arrais Neto, Universidade Federal do Ceará - UFC, Brasil

Prof. Dr. Arno Münster, Universidade de Amiens - Paris, França 